\title{
Bioinformatic analysis reveals possible response of the Arabidopsis acetylated histone-binding protein (BRAT1) against abiotic stresses
}

\section{Asaad M. Mahmood}

Department of Biology, College of Education, University of Garmian, Kalar, Al- Sulaimaniyah, Kurdistan Region, Iraq

Email: asaad@garmian.edu.krd

\section{Abstract}

Transposable elements and other sequences of repetitive DNA including microsatellite are usually subject to both DNA methylation and transcriptional silencing. However, anti-silencing mechanisms which lead to promote transcription in such regions are not well investigated. A recent genetic screening in Arabidopsis thaliana identified an anti-silencing factor, named Bromodomain and ATPase domain-containing protein 1 (BRAT1). This protein is involved in DNA demethylation through a valuable association between histone acetylation and transcriptional anti-silencing at methylated genomic loci. This involvement can be conserved in eukaryotes. Although protein acts as an anti-silencing factor, there is no previous study identifies its contribution in gene regulation under unfavorable conditions. This study was analyzed several molecular patterns of the respective gene including protein-protein interactions, Nuclear Localization Signals (NLS), Cis regulatory elements (CREs) and intron-mediated enhancement (IMEter) using recent bioinformatic data bases. Results showed protein-protein interactions between the respective gene product and other proteins are involved against abiotic stresses, the protein of this gene is localized in nucleus. Results were also observed several CREs of non-coding regions representing their roles as stresses-responsive factors, according to IMEter analysis, this response is expected to valuably present in Intron 1, suggesting experimental studies on mutant lines that contain insertions in their non-coding regions specifically intron 1of the underlying gene.

Keywords: Transposable elements, DNA methylation, Histone acetylation, BRAT1, Abiotic stresses

\section{Introduction}

DNA methylation is considered as an important chromatin modification which play roles in regulation of transposable element (TE) and transgene silencing, and to stabilize, imprint and regulate genome (1,2), DNA methylation in Arabidopsis thalianais enriched with TEs and other repetitive DNA sequences including microsatellites(2). The concentration of DNA methylation can be either diluted 
passively during DNA replication or reduced markedly by active DNA demethylation modifiers (3, 4) including DNA glycosylase ROS1 (5), DML2 and DML3, and DME in DNA demethylation that they are subsequently involved to prevent transcriptional silencing (6).

A histone acetyltransferase named IDM1 is responsible to acetylate histone marks that are required for active DNA demethylation by ROS1 and then activating gene transcription $(7,8)$. However, the mechanisms that recognize acetylated histone marks which subsequently mediates DNA demethylation and anti-silencing are still unknown.

Bromodomain is regarded as an acetylated histone interaction module which is found in different types of nuclear proteins such as histone acetyltransferases, chromatin remodeling factors and transcriptional coactivators(9).

Previous studies have been determined bromodomain-containing proteins in Arabidopsis(10). A type of this protein including bromodomain protein BRAHMA (BRM) is involved in stress response(11). In Arabidopsis, another important member of a sub-group of bromodomain proteins (BET) functions as general transcription factors. Three of these transcription factors namely GTE4, GTE1/IMB1 and GTE6 are functionally found to involve in cell division, seed germination, and leaf development, respectively (12).

It is recently found that BRAT1 (Bromodomain and ATPase domain-containing protein 1) acts asan anti-silencing factor. They demonstrated that the bromodomain of BRAT1 is able to bind to acetylated histone and then influences levels of histone acetylation at methylated genomic regions; thereby they provided a potential link between each histone acetylation and anti-silencing factors and subsequently prevent transcriptional silencing $(13,14)$. However, there are no previous studies to confirm the contribution of the responsible gene (At lg05910.1) of bromodomain of BRAT1 against abiotic stresses. In order to understand the contribution of the respective gene in regulating gene expression under stress conditions, we analyzed the landscape of regulatory elements of this gene and determined its link with responsible genes that are involved against abiotic stress

\section{Material and Methods}

The present study was carried out during February to May, 2018. Here we used different bioinformatic software including String V9.1(15), Support Vector Machinebased localization predictor (AtSuP)(16), Database of Plant cis-acting Regulatory DNA elements(17)andIMEter (version 2.0)(14).

\subsection{Protein-protein interactions}

Protein-protein interaction networks using String V9.1 (http://string-db.org/) were investigated to study associations and integrations between the respective protein and 
other proteins are either involved in DNA methylation and demethylation or contributed in plant adaptation to unfavourable conditions.

\subsection{Nuclear Localization Signal (NLS)}

In order to predict the intracellular localisation of the proteinof respective gene (AT1G05910.1 or Brat1) in Arabidopsis, protein sequences were analysed using Support Vector Machine-based localization predictor (AtSuP) programme which has seven possible categories, nucleus, mitochondrion, chloroplast, cytoplasm, plasma membrane, golgi apparatus and plasma membrane.

The software analysis included four options namely Amino acid composition-based, Dipeptide composition-based, N-Center-C terminal based and Best hybrid-based classifier (AA+PSSM+N-Center-C+PSI-BLAST).

\subsection{Introniccis element analysis}

To identify cisregulatory elements (CREs) of AT1G05910.1, intronic regions of this gene were identifiedfrom TAIR (http://www.Arabidopsis.org/). The FASTA of this gene was obtained from NCBI (>NC_003070.9:1790216-1796715 Arabidopsis thaliana chromosome 1 sequence).To determine intronic cis regulatory elements, the sequence of each intron was filtered using the PLACE database (Database of Plant cis-acting Regulatory DNA elements; http://www.dna.affrc.go.jp/PLACE/). In addition, intron-mediated enhancement (IME) signals were obtained for each intron sequence using IMEter software (version 2.0) http://korflab.ucdavis.edu/cgi-bin/webimeter2.pl.

\section{Results and Discussion}

\subsection{Protein-protein interactions}

To determine whether the activities of the respective gene product (protein) directly affect enzymes are involved in epigenetic regulation namely DNA methylation and demethylation, abiotic stress such as drought, dehydration, heat, cold and lights. Protein-protein interactions in association with physical and biological activities were investigated using String bioinformatics software.

The results presented in Figure 1, show strong protein links between the respective proteins and BRM, GTE6 and products of AT3G15120 in A. thaliana. BRM intermediates valuable interactions between the respective protein with five important drought-responsive proteins including Transcription factor MYC2, MYB2(18), DREB2A, ERD1 and RD22(19). Moreover, through methyl transferase 1 (MET1), the respective gene product is also interacts with many epigenetic modifiers such as CMT3, DRM1, DRM2, ROS4, DML1 and DML2(18). 


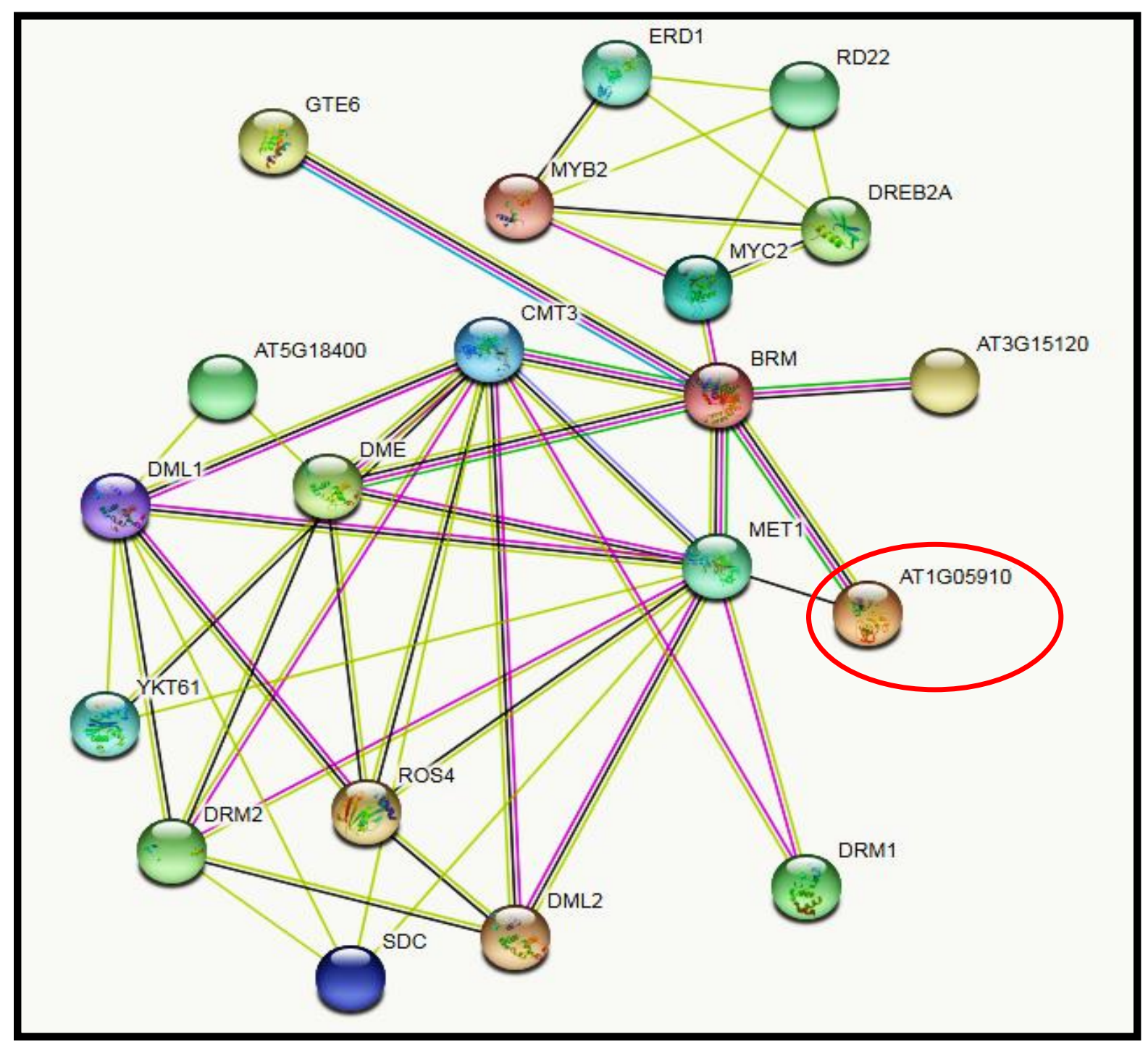

Figure 1. Protein-protein links between respective gene product (BRAT1) and other epigenetic modifiers and proteins that are involved in responding to abiotic stress in A. thaliana (http://stringdb.org/).

In a relevant study, it is revealed that the BRAT1 mediates DNA demethylation (active removal of DNA methylation) at a small set of loci targeted through the involvement of the 5-methylcytosine DNA glycosylase ROS1.Moreover, the action of BRAT1 as an anti-silencing protein is largely independent of DNA demethylation. These researchers were also demonstrated that the bromodomain of BRAT1 is able to bind to acetylated histone, which might consequently act an anti-transcriptional silencing protein(13). Does this important involvement an anti-transcriptional silencing protein play roles in tolerations to abiotic stress? Previous studies have been demonstrated biological links between this protein and other epigenetic modifiers. 
However, interactions between BRAT1 and other stress-responsive proteins haven't been documented yet.

Our results represent protein-protein interactions between the target proteins and BRM (is involved in stress response and phytohormone signalling, GTE6 (is involved in leaf development) and products of AT3G15120 (contribute in histone acetylation) in A. thaliana (20-23). This result indicates active contribution of the respect gene product to regulate epigenetic modification, plant development and importantly stress conditions.

Furthermore, the Figure1 also identified important interactions of the studied protein with several important proteins including:- (I) Transcription factor MYC2, an enzyme is involved in response to oxidative stress and immunity in plant(24); (II) MYB2an enzyme is contributed to regulate the expression of dehydration-responsive genes(25),(III) DREB2A is another important protein that interacts with the respective protein through BRM, microarray and RNA gel blot analyses have been confirmed that the overexpression of transcriptional activation domain of DREB2Aled to significant drought stress tolerance in Arabidopsis plants (26),(IV) ERD1 that known to help the recovery of plants from drought stress and is involved in the biosynthesis of proline $(27,28)$, (IVI) RD22, an enzyme linked to the dehydration-induced by Abscisic acid (29). These findings opened a way for further investigations such as the contribution of regulatory region of introns of the respective gene against abiotic stresses.

\subsection{Prediction of Nuclear Localization Signal (NLS)}

To further investigate the action place of the respective gene product, we analyzed its active motifs and their localization in the cell. Prediction of nuclear localization signal showed similar patterns of amino acid residues (Table 1). The analysis predicted the presence of NLS to the nucleus for the protein encoded by the respective gene. Moreover, all methods including Amino Acid composition based SVM, Dipeptide composition (sequence-order) based, N-Center-C terminal (3parts) based, PSI-BLAST (similarity-search) prediction and AA+NCC+PSIBLAST+PSSM (best hybrid) based were shown the localization of the respective gene product in the nucleus.

Table 1. Prediction of subcellular localization of the protein of AT1G05910.1 using BLAST

\begin{tabular}{|l|l|}
\hline \multicolumn{1}{|c|}{ Method } & \multicolumn{1}{c|}{ Subcellular localization } \\
\hline Amino Acid composition based SVM & Nucleus \\
\hline Dipeptide composition (sequence-order) based & Nucleus \\
\hline N-Center-C terminal (3-parts) based & Nucleus \\
\hline PSI-BLAST (similarity-search) prediction & Nucleus \\
\hline AA+NCC+PSI-BLAST+PSSM (best hybrid) based & Nucleus \\
\hline
\end{tabular}

AtSubP $=$ http://bioinfo3.noble.org/AtSubP/?dowhat=AtSubP 
Results from this analysis showed similarities between methods used to predict the localization of the respective protein. These results demonstrated nucleus localization of the BRAT1, which is predicted to be useful in understanding the functional variety of proteins involved in histone acetylation and DNA demethylation and subsequently in regulating responses against stress conditions, including the exact role of the target protein and its regulatory signals. A relevant review was stated that a specific nuclear signal transduction regulates expression of specific gene sets, which consequently leads to an appropriate response to stress conditions(30). Interestingly, components of these pathways are subjected to post-translational modifications as well as epigenetic changes. Nuclear protein acetylation and/or deacetylation are important posttranslational modifications that play major roles in the regulation of gene expression (31).

In light of this, in order to understand the precise localisation of this protein in response to unfavourable conditions, it would be important to experimentally study the subcellular localisation of BRAT1 protein, for example with techniques using green fluorescent protein (GFP) $(32,33)$. These techniques will be valuable to understand mechanisms that modulate gene expression under different environmental conditions. Due to its link to epigenetic modifiers and its localization in nucleus, a precise analysis to determine regulatory elements in the non-coding region of this gene can be of interest.

\subsection{Landscape of regulatory elements of AT1G05910.1}

Following obtaining interesting predictions in regards to protein-protein interactions of the respective gene product and showing active localization (nucleus). We further analyzed Cis-regulatory elements (CREs) of the target gene.

Identification of known motifs in a given gene provides possible insight into the functional characterization of that gene and predicts potential co-expressed genes. The analysis presented here, describes the distribution of important cis elements that are contributed effectively against abiotic stresses of respective gene (6592bp). The distribution and locations of important motifs within regions of this gene are given in Error! Reference source not found..

1 AAAAAAAGAAAAAACGTTCGAAGAGGAAAAAAAAAAAAGAGGGAGAAGAG (+) GT1CONSENSUS [GRWAAW]

(+) GT1GMSCAM4 [GAAAAA]

(-) ACGTATERD1 [ACGT]

(+) ACGTATERD1[ACGT]

201 TGTCAGTTGATTNTGTCTCCTCCAGTTCTTTGGCTAATGCAATCGGATAA (-) MYB2CONSENSUSAT [YAACKG] 
(+) MYBCORE[CNGTTR]

245 GGATA

(+) IBOXCORE [GATAA]

251 ACAGTCGTTTTAGCAGTTATTTGCAAGGATTTGNTTTATATTTCTCAACA

(-) MYB2AT [TAACTG]

651 ATAGGCTTAGGAGGAGGCCCAAATTGCATGGTCGCTCATACTTGTACTAC

(-) SITEIIATCYTC [TGGGCY]

801 GAGGGCATCAAATGCCGCGGTAAGCATTACATGTTTCTTCCTATGATATT

(-) CGCGBOXAT [VCGCGB]

(+) CGCGBOXAT [VCGCGB]

1051 CCGTTTTTTTTTTGNTCTCATTAAACCAGAATGTTTATACATTTGCTAAT

(+) MYB1AT [WAACCA]

1101 GACGTACAGCCAATTGCATCTGATCTCCGGCGTTCNCACGAGGAAGAGAA

(+) CCAATBOX1 [CCAAT]

1951 GCACCTTGGCTATTTGGGGGTTTGGACACGTATGGGTNCAAGTTCATTGG

(-) ZDNAFORMINGATCAB1 [ATACGTGT]

2301 CGAGCATTAGCATGTGCTGCTTCAAAAGCTGGACAGAAAGTTNAGCTTTT

(-) MYCATRD2 [CACATG]

(+) MYCATERD1[CATGTG]

2651 GAGTTTAATTTTTCCTTACCAGGTTGCGAAGCACGAGCCGAAATATTNGG

(+) LTRE1HVBLT49 [CCGAAA]

2851 TTATACCAGTGATGATAAATACGCCATAGATGTTGGGTTGGTTAATGTTG

(+) GT1CORE [GGTTAA]

3801 TTTTGTTATCCCATAAAAGCTGGTAGGGCACTTNTCTTTGAAAGTCGGTC

(-) DRE2COREZMRAB17[ACCGAC]

Figure 2. AT1G05910.1 analysis. Motifs with similar coloured fonts represent similar motifs related to adverse environmental conditions. $(+)=$ Forward strand and $(-)=$ Reverse strand.

In addition, intron sequences are also important in transcriptional regulation. In regards to the investigated elements, different motifs which regulate the transcription of genes are involved in controlling plants against unfavorable conditions were found for intron (10 introns) of the target gene. To identify the effective location of BRAT1 as an anti-silencing factor, all intronic regions of this gene were analyzed to demonstrate the distribution CREs in all introns and to identify the most effective (by sensing or signaling) fragment against abiotic stresses. The location, sequence length (bps) and Cis regulatory elements for each intron of the respective are given in Table. 
Table 2: Intronic location, length and number of CREs in the introns of AT1G05910.1

\begin{tabular}{|cccc}
\hline Introns & Location & bps & Number of CREs \\
\hline Intron 1 & $132-538$ & 406 & 65 \\
\hline Intron 2 & $809-1094$ & 285 & 57 \\
\hline Intron 3 & $1197-1302$ & 105 & 17 \\
\hline Intron 4 & $3127-3207$ & 80 & 11 \\
\hline Intron 5 & $3397-3543$ & 146 & 22 \\
\hline Intron 6 & $3681-4194$ & 513 & 87 \\
\hline Intron 7 & $4438-4855$ & 417 & 61 \\
\hline Intron 8 & $5043-5312$ & 269 & 21 \\
\hline Intron 9 & $5379-5490$ & 111 & 14 \\
\hline Intron 10 & $5741-5881$ & 140 & 20 \\
\hline
\end{tabular}

This table shows that the two longest introns are introns 6 and 7containing 513 and 417 base pairs respectively. However, the two shortest introns are identified to be introns 4 and 5 possessing 80 and 105 base pairs respectively. The highest numbers of CREs (87 and 65) are respectively found in introns 6 and 1. In contrast, both introns 4 and 9 are given the lowest of CREs occupying only 11 and 14 elements respectively.

To further understand the richest intron with CREs, these elements are shown in percentage rates (Figure 3).

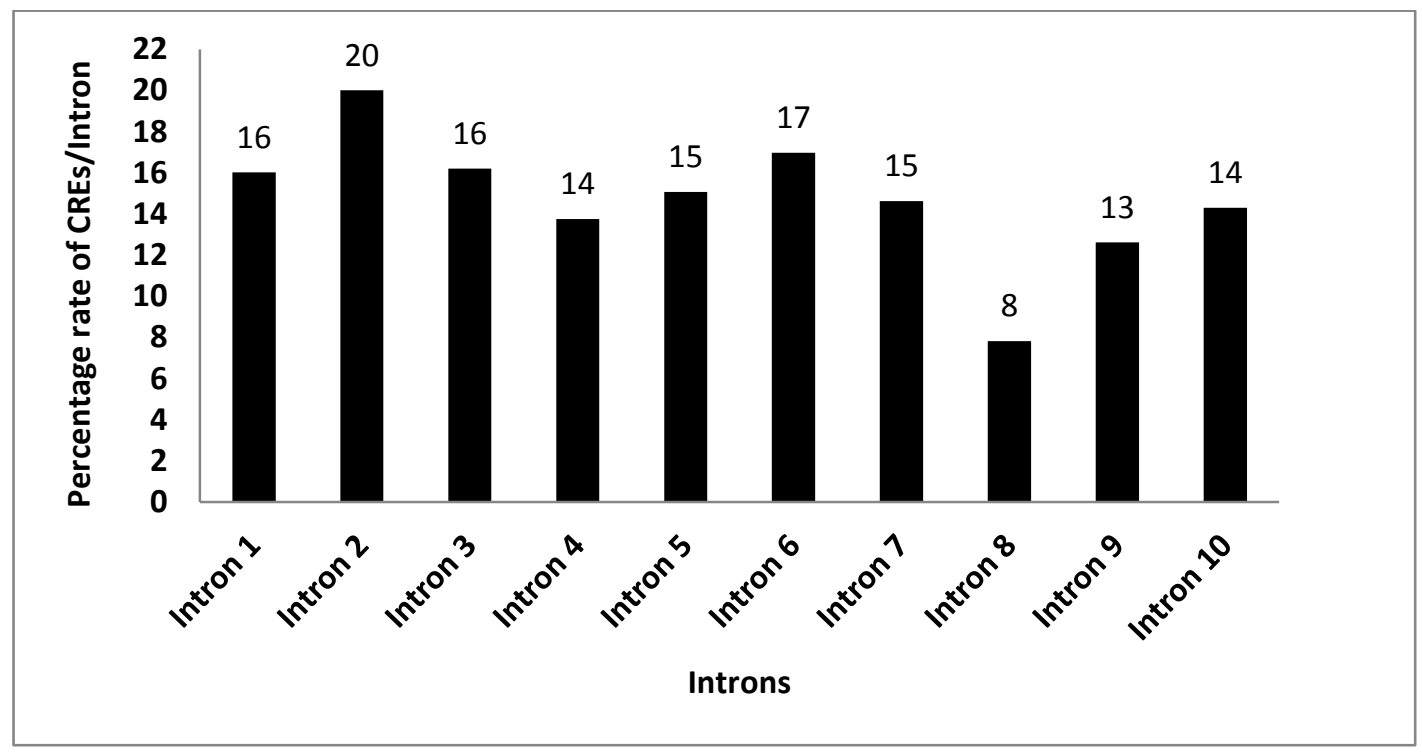

Figure 3. Percentage rate of cis regulatory elements in intronic regions of Brat1. 
The highest percentage of CREs are counted in intron 2 (20\%) which follows by intron $6(17 \%), 1$ and $2(16 \%)$. In order to determine which intron is likely enhances gene expression; we calculated the intron-mediated enhancement (IMEter) for each intron. The higher the IMEter the score, the more likely the intron is expected to enhance expression(34). Our results show that the intron 1 and 10 are given the highest IMEter score (20.8 and 8.0 respectively), demonstrating most likely gene expression enhancer. Whereas, the smallest score of IMEter (1.2) was shown by intron 9 (Figure 4).

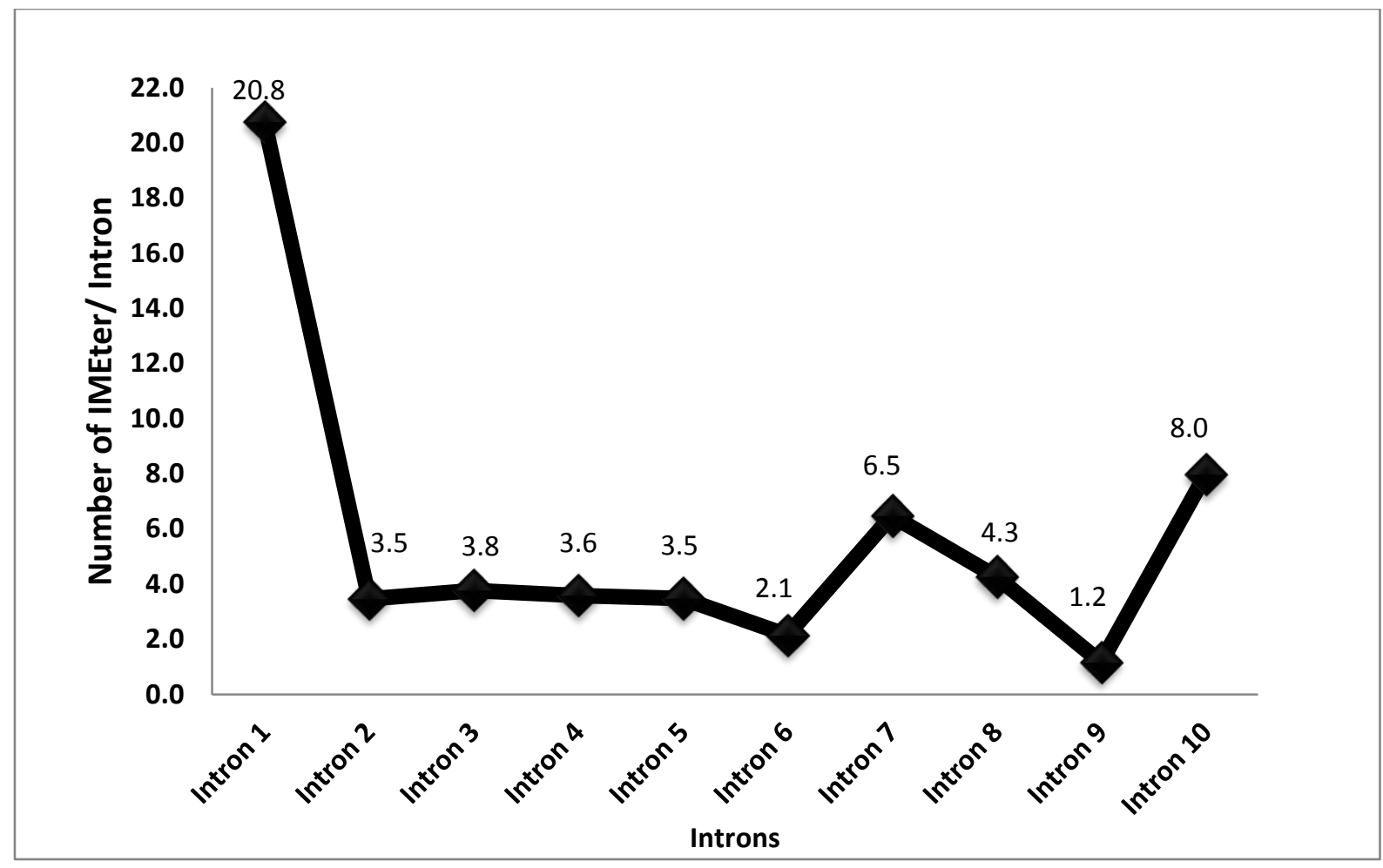

Figure 4. Distribution of IMEter v2.0 scores across each intron of Brat1.

Introns with an (IMEter) v2.0 score above 20: introns that can strongly enhance gene expression Introns with an (IMEter) v2.0 score under 10: introns that less likely enhance gene expression.

CREs such as enhancers and promoters are regions/sequences of non-coding DNA that regulate gene expression. Mutations that affect the function of these regions/sequences may lead to phenotypic diversity within and between species(35, 36). Motifs that are common to the promoters of several genes may represent a key signature for a family of co-regulated genes with such motifs usually being involved with a variety of complex interactions with transcription factors (37). Additionally, single motifs may bind different transcription factors thereby bringing genes under multiple regulatory controls.

A recent study was found active contribution of de novo mutations in regulatory elements of non-coding region (introns) to the neuro-developmental disorders, 
This set of genetically heterogeneous of disorders might play roles to combine functional and evolutionary evidences, which is important to identify regulatory causes of genetic disorders such as fetal brain diseases(38).In the current study, we determined regulatory region of introns of the respective gene in order to understand its possible roles against abiotic stresses as well as evolutionary patterns.

CREs analysis shows the presence of (GT1CONSENSUS, GT1GMSCAM4), these elements are light and salinity- responsive factors (39-41). In addition, CCAATBOX1 is involved cooperatively with heat shock elements (HSEs) to increase adaptations to heat shock $(42,43)$.ZDNAFORMINGATCAB1 is also involved in light-dependent developmental expression of the gene(44). LTRE1HVBLT49 is a cold-responsive element(45, 46), which we found in the intronic regions of the respective gene sequence

Within this sequence, ACGTATERD1 factor containing (ACGT) was found, this sequence is required for etiolation-induced expression of early responsive to dehydration (erd1) which is actively involved in the upregulation of gene expression under water stress conditions (47).

All elements including MYB2CONSENSUSAT, MYBCORE, MYB2AT, MYCATRD2, MYCATERD1 and DRE2COREZMRAB17 that they belong to MYBs were determined in the non-coding regions specifically introns of the target gene. Previous studies recognized that MYB site was found in the promoters of the dehydration-responsive gene (rd22) Arabidopsis. Furthermore, binding site for all animal MYB and Arabidopsis MYB proteins including ATMYB1 and ATMYB2 are involved in regulation of genes that are responsive to water stress (48-53).

These results indicate the presence of several elements that are valuably involved in gene regulations under abiotic stresses such as light, salinity and drought. In order to investigate the distributions of regulatory elements within intronic regions of the target gene, the highest percentage rate of such elements were found in intron 2 followed by intron 6 and 1 respectively.

This finding followed by further investigation including IMEter, this analysis shows the positive effect of introns on gene expression in which introns with higher IMEter score represents higher potential on gene expression(14). Results showed that intron 1 possesses higher score in comparison with other introns; this means the most effective non-coding region of the respective gene is intron 1. Moreover, any mutation such as insertion within this sequence can be much valuable than other regions.

In conclusion, presumably, this gene is involved in epigenetic regulations and specifically establishing a link between histone acetylation and DNA demethylation leading anti-silencing transcriptions. Protein-protein interaction demonstrated vital links between the respective gene and others that are stresses-responsive. The 
presence of several Cis regulatory elements of stresses-responsive factors in the noncoding regions of Bratl might confirm this link. Due to its localization in nucleus, this gene might effectively involve in regulating histone acetylation and subsequently adaptation to unfavourable conditions. In order to experientially confirm this involvement, it is recommended to use mutant lines containing insertions in their first intron because it has the highest IMEter and it is expected to play much effective role in the regulation of post-transcriptional mechanisms.

\section{References}

1. Hindorff LA, Sethupathy P, Junkins HA, Ramos EM, Mehta JP, Collins FS, et al. Potential etiologic and functional implications of genome-wide association loci for human diseases and traits. Proceedings of the National Academy of Sciences. 2009;106(23):9362-7.

2. Maurano MT, Humbert R, Rynes E, Thurman RE, Haugen E, Wang H, et al. Systematic localization of common disease-associated variation in regulatory DNA. Science. 2012:1222794.

3. Hill RE, Lettice LA. Alterations to the remote control of Shh gene expression cause congenital abnormalities. Philosophical Transactions of the Royal Society B: Biological Sciences. 2013;368(1620):20120357.

4. Naville M, Ishibashi M, Ferg M, Bengani H, Rinkwitz S, Krecsmarik M, et al. Long-range evolutionary constraints reveal cis-regulatory interactions on the human X chromosome. Nature communications. 2015;6:6904.

5. Köhler S, Vasilevsky N, Engelstad M, Foster E, McMurry J, Aymé S, et al. The human phenotype ontology in 2017. 2017.

6. Wright CF, Fitzgerald TW, Jones WD, Clayton S, McRae JF, Van Kogelenberg $\mathrm{M}$, et al. Genetic diagnosis of developmental disorders in the DDD study: a scalable analysis of genome-wide research data. The Lancet. 2015;385(9975):1305-14.

7. McRae JF, Clayton S, Fitzgerald TW, Kaplanis J, Prigmore E, Rajan D, et al. Prevalence and architecture of de novo mutations in developmental disorders. Nature. 2017;542(7642):433.

8. Lek M, Karczewski KJ, Minikel EV, Samocha KE, Banks E, Fennell T, et al. Analysis of protein-coding genetic variation in 60,706 humans. Nature. 2016;536(7616):285.

9. Koren A, Handsaker RE, Kamitaki N, Karlić R, Ghosh S, Polak P, et al. Genetic variation in human DNA replication timing. Cell. 2014;159(5):1015-26.

10. Kong A, Thorleifsson G, Gudbjartsson DF, Masson G, Sigurdsson A, Jonasdottir A, et al. Fine-scale recombination rate differences between sexes, populations and individuals. Nature. 2010;467(7319):1099. 
11. Gao T, He B, Liu S, Zhu H, Tan K, Qian J. EnhancerAtlas: a resource for enhancer annotation and analysis in 105 human cell/tissue types. Bioinformatics. 2016;32(23):3543-51.

12. Shooshtari $\mathrm{P}$, Huang $\mathrm{H}$, Cotsapas $\mathrm{C}$. Integrative genetic and epigenetic analysis uncovers regulatory mechanisms of autoimmune disease. The American Journal of Human Genetics. 2017;101(1):75-86.

13. Zhang C-J, Hou X-M, Tan L-M, Shao C-R, Huang H-W, Li Y-Q, et al. The Arabidopsis acetylated histone-binding protein BRAT1 forms a complex with BRP1 and prevents transcriptional silencing. Nature communications. 2016;7:11715.

14. Rose AB, Elfersi T, Parra G, Korf I. Promoter-proximal introns in Arabidopsis thaliana are enriched in dispersed signals that elevate gene expression. The Plant Cell. 2008;20(3):543-51.

15. Bao W, He F, Gao J, Meng F, Zou H, Luo B. Alpha-1-antitrypsin: a novel predictor for long-term recovery of chronic disorder of consciousness. Expert review of molecular diagnostics. 2018;18(3):307-13.

16. Kaundal R, Saini R, Zhao PX. Combining machine learning and homology-based approaches to accurately predict subcellular localization in Arabidopsis thaliana. Plant physiology. 2010:pp. 110.156851.

17. Higo K, Ugawa Y, Iwamoto M, Korenaga T. Plant cis-acting regulatory DNA elements (PLACE) database: 1999. Nucleic acids research. 1999;27(1):297-300.

18. Grzybkowska D, Morończyk J, Wójcikowska B, Gaj MD. Azacitidine (5-AzaC)treatment and mutations in DNA methylase genes affect embryogenic response and expression of the genes that are involved in somatic embryogenesis in Arabidopsis. Plant Growth Regulation. 2018;85(2):243-56.

19. Lu X, Zhang X, Duan H, Lian C, Liu C, Yin W, et al. Three stress-responsive NAC transcription factors from Populus euphratica differentially regulate salt and drought tolerance in transgenic plants. Physiologia plantarum. 2018;162(1):73-97.

20. Efroni I, Han S-K, Kim HJ, Wu M-F, Steiner E, Birnbaum KD, et al. Regulation of leaf maturation by chromatin-mediated modulation of cytokinin responses. Developmental cell. 2013;24(4):438-45.

21. Han S-K, Sang Y, Rodrigues A, Wu M-F, Rodriguez PL, Wagner D. The SWI2/SNF2 chromatin remodeling ATPase BRAHMA represses abscisic acid responses in the absence of the stress stimulus in Arabidopsis. The Plant Cell. 2012:tpc. 112.105114.

22. Wu M-F, Sang Y, Bezhani S, Yamaguchi N, Han S-K, Li Z, et al. SWI2/SNF2 chromatin remodeling ATPases overcome polycomb repression and control floral organ identity with the LEAFY and SEPALLATA3 transcription factors. Proceedings of the National Academy of Sciences. 2012;109(9):3576-81. 
23. Wang J, Tadeo X, Hou H, Tu PG, Thompson J, Yates JR, et al. Epe1 recruits BET family bromodomain protein Bdf2 to establish heterochromatin boundaries. Genes \& development. 2013;27(17):1886-902.

24. Cui H, Qiu J, Zhou Y, Bhandari DD, Zhao C, Bautor J, et al. Antagonism of transcription factor MYC2 by EDS1/PAD4 complexes bolsters salicylic acid defense in Arabidopsis effector-triggered immunity. Molecular Plant. 2018.

25. Gaponenko A, Shulga O, Mishutkina Y, Tsarkova E, Timoshenko A, Spechenkova N. Perspectives of Use of Transcription Factors for Improving Resistance of Wheat Productive Varieties to Abiotic Stresses by Transgenic Technologies. Russian Journal of Genetics. 2018;54(1):27-35.

26. Reis RR, da Cunha BADB, Martins PK, Martins MTB, Alekcevetch JC, ChalfunJúnior A, et al. Induced over-expression of AtDREB2A CA improves drought tolerance in sugarcane. Plant science. 2014;221:59-68.

27. Cecchini NM, Monteoliva MI, Alvarez ME. Proline dehydrogenase contributes to pathogen defense in Arabidopsis. Plant Physiology. 2011;155(4):1947-59.

28. Borges AA, Jiménez-Arias D, Expósito-Rodríguez M, Sandalio LM, Pérez JA. Priming crops against biotic and abiotic stresses: MSB as a tool for studying mechanisms. Frontiers in plant science. 2014;5:642.

29. Yamaguchi-Shinozaki K, Shinozaki K. The plant hormone abscisic acid mediates the drought-induced expression but not the seed-specific expression of rd22, a gene responsive to dehydration stress in Arabidopsis thaliana. Molecular and General Genetics MGG. 1993;238(1-2):17-25.

30. Grandperret V, NICOLAS-FRANCÈS V, Wendehenne D, Bourque S. Type-II histone deacetylases: elusive plant nuclear signal transducers. Plant, cell \& environment. 2014;37(6):1259-69.

31. Chen ZJ, Tian L. Roles of dynamic and reversible histone acetylation in plant development and polyploidy. Biochimica et Biophysica Acta (BBA)-Gene Structure and Expression. 2007;1769(5-6):295-307.

32. Bakhoum SF, Ngo B, Laughney AM, Cavallo J-A, Murphy CJ, Ly P, et al. Chromosomal instability drives metastasis through a cytosolic DNA response. Nature. 2018.

33. Etchegaray J-P, Chavez L, Huang Y, Ross KN, Choi J, Martinez-Pastor B, et al. The histone deacetylase SIRT6 controls embryonic stem cell fate via TETmediated production of 5-hydroxymethylcytosine. Nature cell biology. 2015;17(5):545.

34. Gallegos JE, Rose AB. Intron-mediated enhancement is not limited to introns. bioRxiv. 2018:269852. 
35. Wittkopp PJ, Kalay G. Cis-regulatory elements: molecular mechanisms and evolutionary processes underlying divergence. Nature Reviews Genetics. 2012;13(1):59.

36. Zhao B, Cao JF, Hu GJ, Chen ZW, Wang LY, Shangguan XX, et al. Core ciselement variation confers subgenome-biased expression of a transcription factor that functions in cotton fiber elongation. New Phytologist. 2018;218(3):1061-75.

37. Wang H, Caruso LV, Downie AB, Perry SE. The embryo MADS domain protein AGAMOUS-Like 15 directly regulates expression of a gene encoding an enzyme involved in gibberellin metabolism. The Plant Cell. 2004;16(5):1206-19.

38. Short PJ, McRae JF, Gallone G, Sifrim A, Won H, Geschwind DH, et al. De novo mutations in regulatory elements in neurodevelopmental disorders. Nature. 2018;555(7698):611.

39. Zhou D-X. Regulatory mechanism of plant gene transcription by GT-elements and GT-factors. Trends in plant science. 1999;4(6):210-4.

40. Park HC, Kim ML, Kang YH, Jeon JM, Yoo JH, Kim MC, et al. Pathogen-and $\mathrm{NaCl}$-induced expression of the SCaM-4 promoter is mediated in part by a GT-1 box that interacts with a GT-1-like transcription factor. Plant physiology. 2004;135(4):2150-61.

41. Li T, Sun J, Li C, Lu Z, Xia J. Cloning and expression analysis of the FvNCED3 gene and its promoter from ash (Fraxinus velutina). Journal of Forestry Research.1-12.

42. Wenkel S, Turck F, Singer K, Gissot L, Le Gourrierec J, Samach A, et al. CONSTANS and the CCAAT box binding complex share a functionally important domain and interact to regulate flowering of Arabidopsis. The Plant Cell. 2006;18(11):2971-84.

43. Srivastava R, Rai KM, Srivastava R. Plant Biosynthetic Engineering Through Transcription Regulation: An Insight into Molecular Mechanisms During Environmental Stress. Biosynthetic Technology and Environmental Challenges: Springer; 2018. p. 51-72.

44. Yadav V, Mallappa C, Gangappa SN, Bhatia S, Chattopadhyay S. A basic helixloop-helix transcription factor in Arabidopsis, MYC2, acts as a repressor of blue light-mediated photomorphogenic growth. The Plant Cell. 2005;17(7):1953-66.

45. Dunn MA, White AJ, Vural S, Hughes MA. Identification of promoter elements in a low-temperature-responsive gene (blt4. 9) from barley (Hordeum vulgare L.). Plant molecular biology. 1998;38(4):551-64.

46. Zhang C, Jia H, Wu W, Wang X, Fang J, Wang C. Functional conservation analysis and expression modes of grape anthocyanin synthesis genes responsive to low temperature stress. Gene. 2015;574(1):168-77. 
47. Simpson SD, Nakashima K, Narusaka Y, Seki M, Shinozaki K, YamaguchiShinozaki K. Two different novel cis-acting elements of erd1, a clpA homologous Arabidopsis gene function in induction by dehydration stress and dark-induced senescence. The Plant Journal. 2003;33(2):259-70.

48. Solano R, Nieto C, Avila J, Canas L, Diaz I, Paz-Ares J. Dual DNA binding specificity of a petal epidermis-specific MYB transcription factor (MYB. Ph3) from Petunia hybrida. The EMBO Journal. 1995;14(8):1773-84.

49. Abe H, Urao T, Ito T, Seki M, Shinozaki K, Yamaguchi-Shinozaki K. Arabidopsis AtMYC2 (bHLH) and AtMYB2 (MYB) function as transcriptional activators in abscisic acid signaling. The Plant Cell. 2003;15(1):63-78.

50. Urao T, Yamaguchi-Shinozaki K, Urao S, Shinozaki K. An Arabidopsis myb homolog is induced by dehydration stress and its gene product binds to the conserved MYB recognition sequence. The Plant Cell. 1993;5(11):1529-39.

51. Busk PK, Pagès M. Regulation of abscisic acid-induced transcription. Plant molecular biology. 1998;37(3):425-35.

52. Dubouzet JG, Sakuma Y, Ito Y, Kasuga M, Dubouzet EG, Miura S, et al. OsDREB genes in rice, Oryza sativa L., encode transcription activators that function in drought-, high-salt-and cold-responsive gene expression. The Plant Journal. 2003;33(4):751-63.

53. Tran L-SP, Nakashima K, Sakuma Y, Simpson SD, Fujita Y, Maruyama K, et al. Isolation and functional analysis of Arabidopsis stress-inducible NAC transcription factors that bind to a drought-responsive cis-element in the early responsive to dehydration stress 1 promoter. The Plant Cell. 2004;16(9):2481-98. 